\title{
Impact of Nitrate Consumption: Case Study of Punjab, India
}

\author{
Anupam Khajuria \\ Tokyo Institute of Technology, Tokyo, Japan \\ Email: khajuria@uncrd.or.jp
}

Received 10 December 2015; accepted 21 February 2016; published 24 February 2016

Copyright (C) 2016 by author and Scientific Research Publishing Inc.

This work is licensed under the Creative Commons Attribution International License (CC BY). http://creativecommons.org/licenses/by/4.0/

c) (i) Open Access

\begin{abstract}
Punjab is one of the most fertile regions in India, where wheat, rice, sugar cane, fruits and vegetables are grown and it is called the "Granary of India" or "India's bread-basket". Rice and wheat are double cropped in Punjab with rice stalks being burned off over millions of acres prior to the planting of wheat. This widespread practice is polluting and wasteful. In Punjab the consumption of fertilizer per hectare is $223.46 \mathrm{~kg}$ as compared to $90 \mathrm{~kg}$ nationally. In recent years a drop in productivity has been observed mainly due to falling fertility of the soil, due to excessive use of fertilizers and pesticides over the years. In this article, we have discussed more details and excess load of fertilizer availability in agricultural purposes. The methodology of this article is to use the data of wheat yield and nitrate consumption. The correlation between nitrate consumption with wheat yield indicates the use of fertilizer in the case of state of Punjab of India.
\end{abstract}

\section{Keywords}

Agriculture, Fertilizers, Nitrogen, Yield, Production, Consumption

\section{Introduction}

India is a country of more than 1000 million people. It is the seventh largest nation in the world with a geographical area of 328.7 million ha. With a net cultivated area of 141 Mha and current cropping intensity of 135\%, the total gross cropped area in India is 190 Mha [1]. With the introduction of modern high yielding varieties and development of irrigation facilities during 2000s, consumption of chemical fertilizer has increased markedly (Figure 1). In 1970-71, consumption of Nitrogen (N) fertilizer was only 0.14 thousand ton, which increased to 10.4 thousand ton in 2000-2001 and rapidly increase in 2011-12 [2]. The annual per capita of cereal production in 1970-71 was $417.6 \mathrm{~g} / \mathrm{capita}$, however the total population was only 551.3 million. The population increased to 1014.8 million in 2000-01, whereas the annual per capita of cereal was significantly increased to $422.7 \mathrm{~g} / \mathrm{capita}$ 
[3]. In spite, the annual per capita of cereal is further drop down to $401 \mathrm{~g} /$ capita by 2010-11 (Figure 2).

Nitrogen is both an essential nutrient and a major pollutant in terrestrial ecosystems. As an integral component of essential plant nutrients, nitrogen plays an important role in increasing crop yields and crop quality [4]. $78 \%$ of gaseous nitrogen $\left(\mathrm{N}_{2}\right)$, appears to be a virtually limitless reservoir, the very strong triple bond between the two nitrogen atoms makes this gas quite inert and not directly usable by plants and animals. Introduction of reactive nitrogen such as nitrate $\left(\mathrm{NO}_{3}^{-}\right)$, ammonium $\left(\mathrm{NH}_{4}^{+}\right)$, or urea, which rapidly hydrolyses to form $\mathrm{NH}_{4}^{+}$, to the terrestrial biosphere, that is, fertilization, has been recognized as the most effective method for increasing food production [5]. However, excess nitrogen used in fertilization has undoubtedly disturbed the biogeochemical

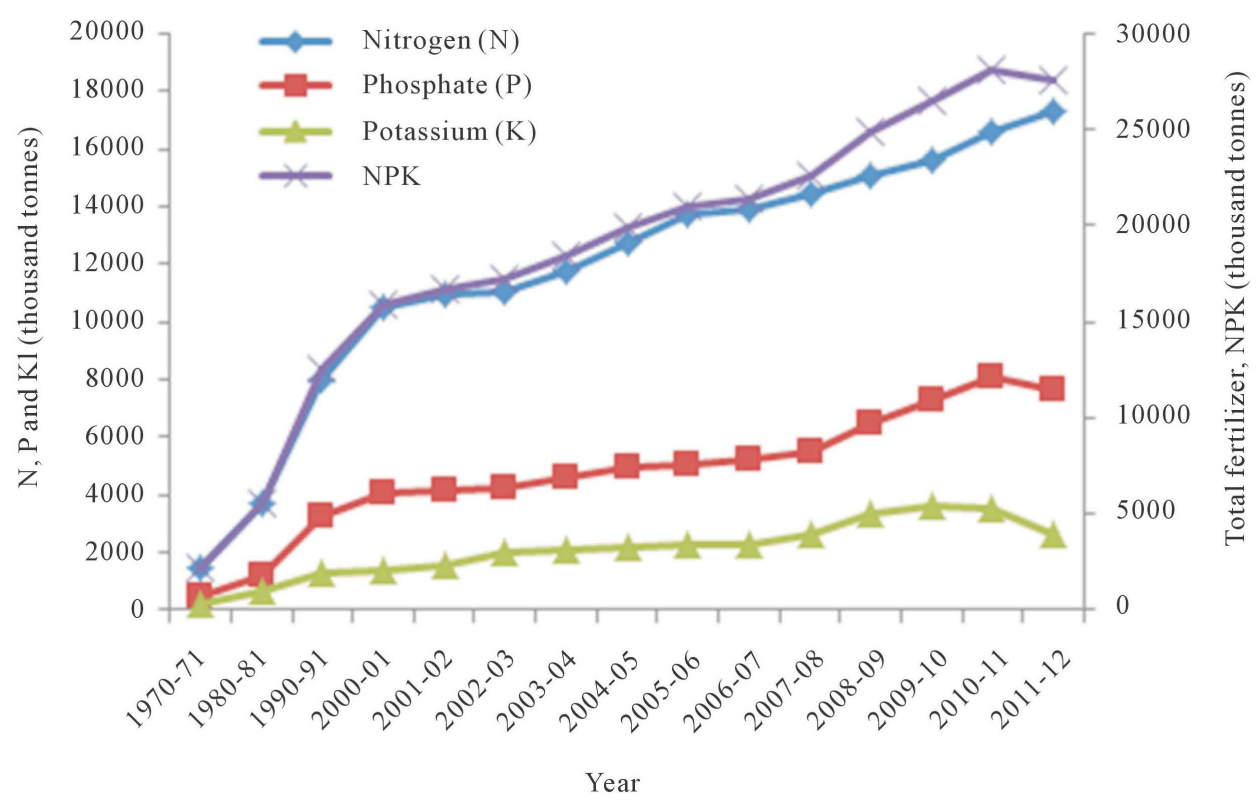

Figure 1. Consumption of fertilizer in India (1970-71 to 2011-12). Source: FAOSTAT (2012).

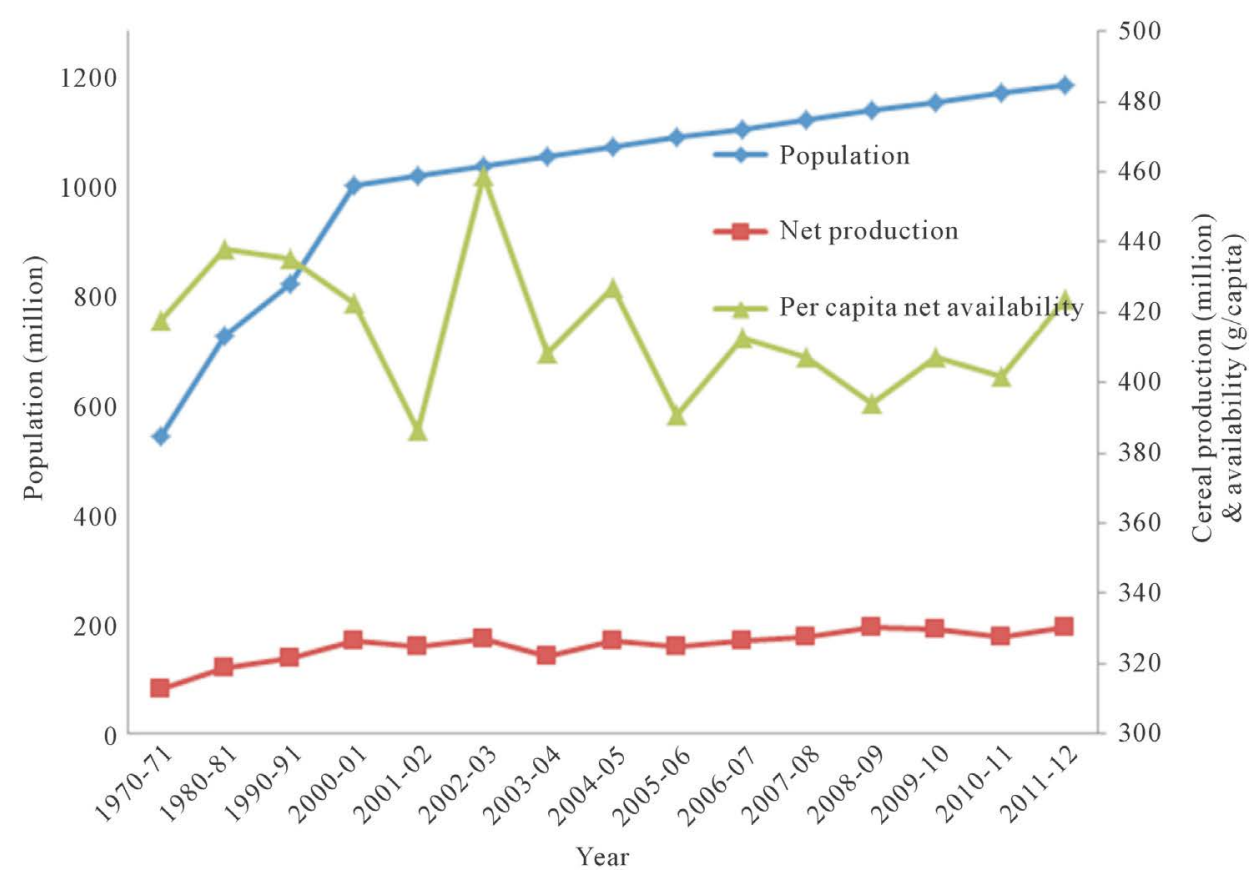

Figure 2. Annual per capita availability and production of cereal and population. Source: FAOSTAT (2012). 
nitrogen cycle of natural ecosystems, resulting in various global, regional, and local environmental problems such as stratospheric ozone depletion, soil acidification, and especially $\mathrm{NO}_{3}^{-}$pollution of ground and surface waters [6]. In contrast to $\mathrm{NH}_{4}^{+}$ions, $\mathrm{NO}_{3}^{-}$ions are not adsorbed by the negatively charged colloids that dominate most soils. Therefore, $\mathrm{NO}_{3}^{-}$ions move downward freely with drainage water and are thus readily leached from the soil. Such leaching losses not only cause several serious environmental problems, but also reduce ecosystem productivity. Figure 3 shows the simplified pathway of nitrogen from atmosphere to create pollution in different pathways.

In this article, we have discussed more details and excess load of fertilizer availability in agricultural purposes and find correlation between nitrate consumption with wheat yield with future prediction in the case of state of Punjab of India.

\section{Phases of Agriculture-Case Study of Punjab, India}

The period from 1950/51 to mid-1960s which is also called pre-green revolution period witnessed tremendous agrarian reforms, institutional changes and development of major irrigation projects. Expansion of area was the main source of growth in the pre-green revolution period. The area expansion diminished considerably in the green revolution period in which growth rate in area was less than half the growth rate in the first period (Figure 4).

Green Revolution technology are the introduction of high yielding varieties of seeds for several major crops, and attain sufficient amount of food grains, creation and utilization of energized well irrigation and lift irrigation facilities, use of high doses of fertilizers and pesticides, and extensive use of farm machinery directed at improving farm productivity [1]. The use of nitrogenous fertilizer used per metric ton of food in the early 1990s called wide coverage phase was between 3.5 to 4 times the amounts used in 1961 and it rapidly increased by mid of 1990s which is called early liberation phase of economy [7]. The consumption of fertilizers (NPK) has been stagnant even the growth rate increase by $3.9 \%$, which differs from area to area during ninth plan. Subsequently, the growth rate of fertilizer has been increased by $4.8 \%$ in Tenth plan phase and continuously increased $6.7 \%$ in the eleventh plan of agricultural sector.

The Punjab state has made a remarkable progress over the last three decades towards feeding the population of state but the rate of growth of population is already much higher than that of production/availability of food grains, similar study done by [8]. The production of food grains in Punjab has increased by $2 \%$ in last 5 years as against $8.6 \%$ rise in population [9]. Since population growth is a major determinant of increase of food demand, there are several indicators of the beginning of an imbalance in supply and demand [10]. The green revolution technology had put great pressure on the ecological system of the Punjab state, leading to a fall in the level of

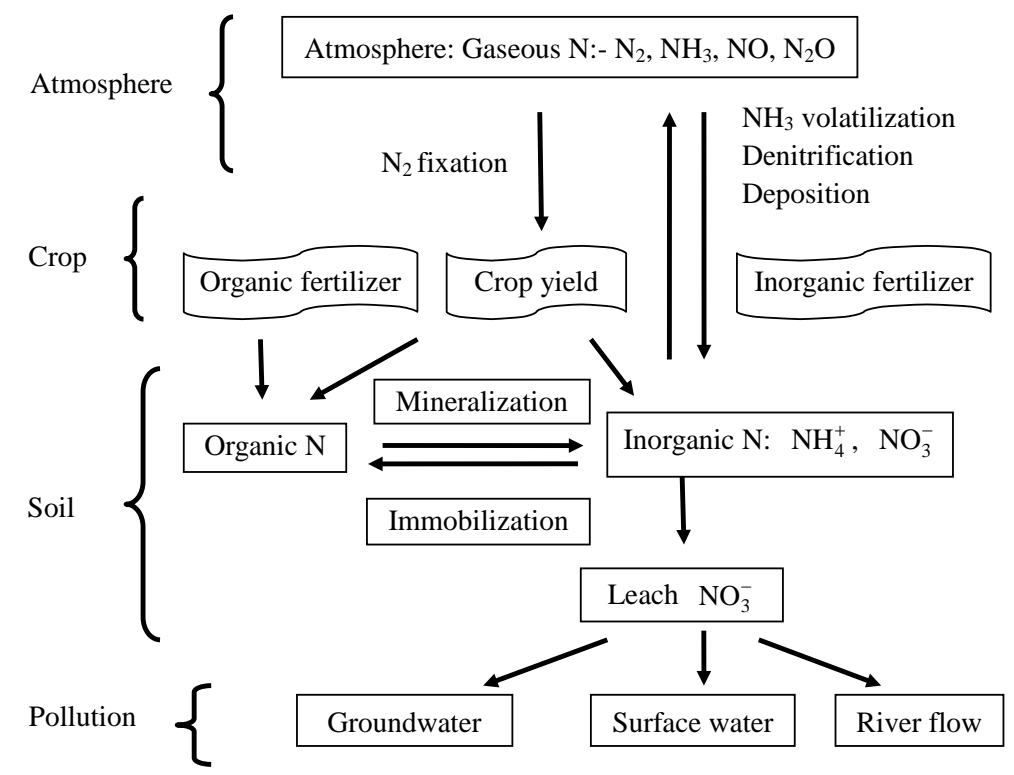

Figure 3. Pathway of Nitrogen from Origin (Atmosphere) towards Crop, Soil and Emit pollution in different water streams. 
ground water table, soil resources deterioration and environmental pollution from farm chemicals [11]. Wheat and rice are highly content with nitrate in respect of other agricultural products (Figure 5). While the high yield of crop production, the growth of chemical fertilizer is increasing with the future prediction [12]. The correlation between cereal production and nitrate consumption has recently increased after 1980s and correlation between nitrate consumption and wheat yield has a very high value of 0.91 as seen in Figure 6 [2]. The time series of nitrate consumption is strongly correlated with the high yield of wheat production same studied in China [13]. The excessive use of fertilizer has resulted is not just higher contents of nitrate in wheat yield it also shows the groundwater contamination which leads to impure water quality in state of Punjab in India.

\section{Conclusion}

The use of fertilizers is seen as a necessary agricultural technology because soil restores nutrients. Even there is a significant potential to increase nitrogen use efficiency at the farm level. This will lead to maintain the requirement

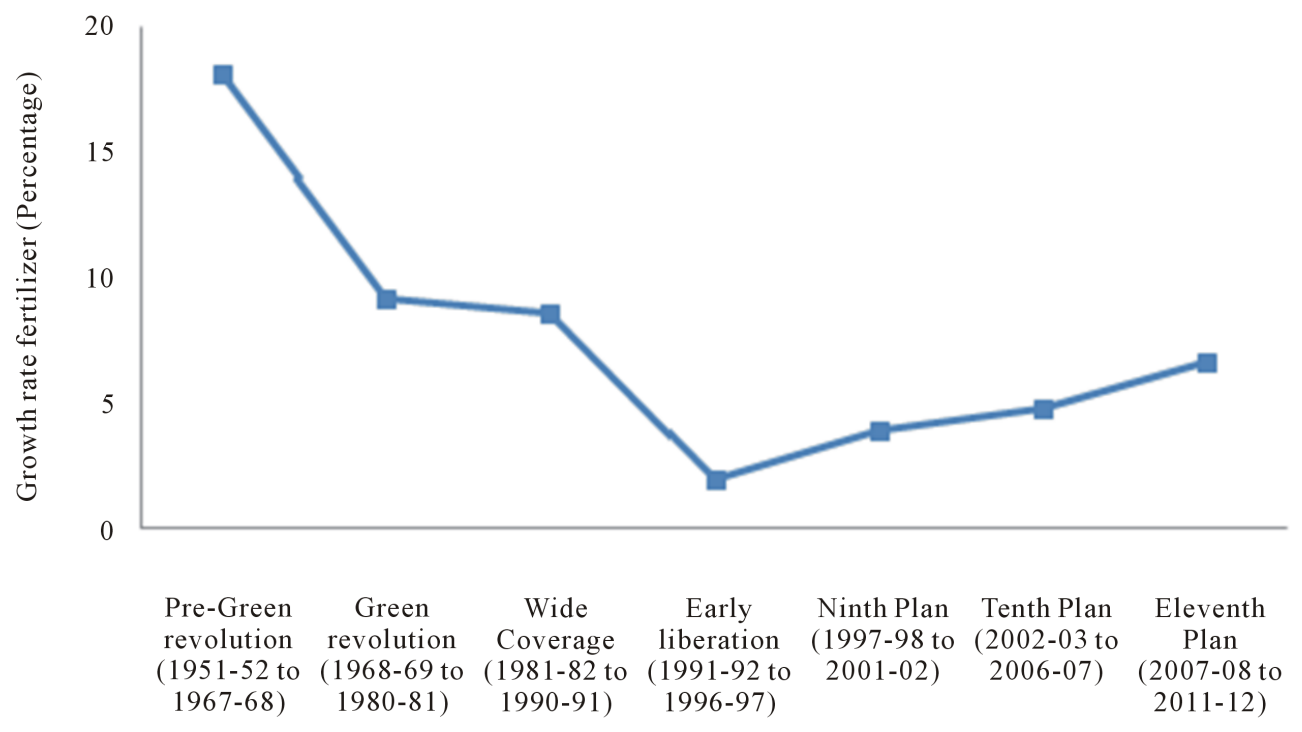

Figure 4. Growth rate of fertilizer in agricultural phase of India. Source: IASRAI (2006).

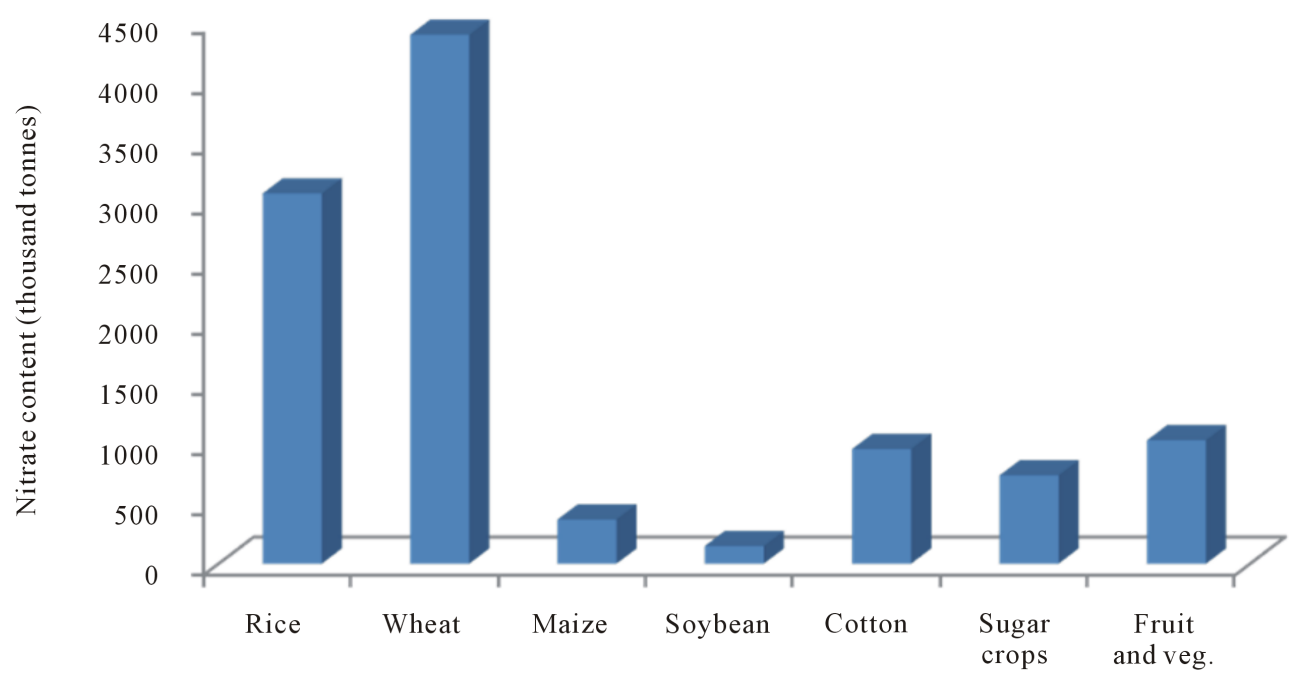

Various agricultural products

Figure 5. Nitrate content in various agricultural products in state of in Punjab. Source: Annual Report (2012). 


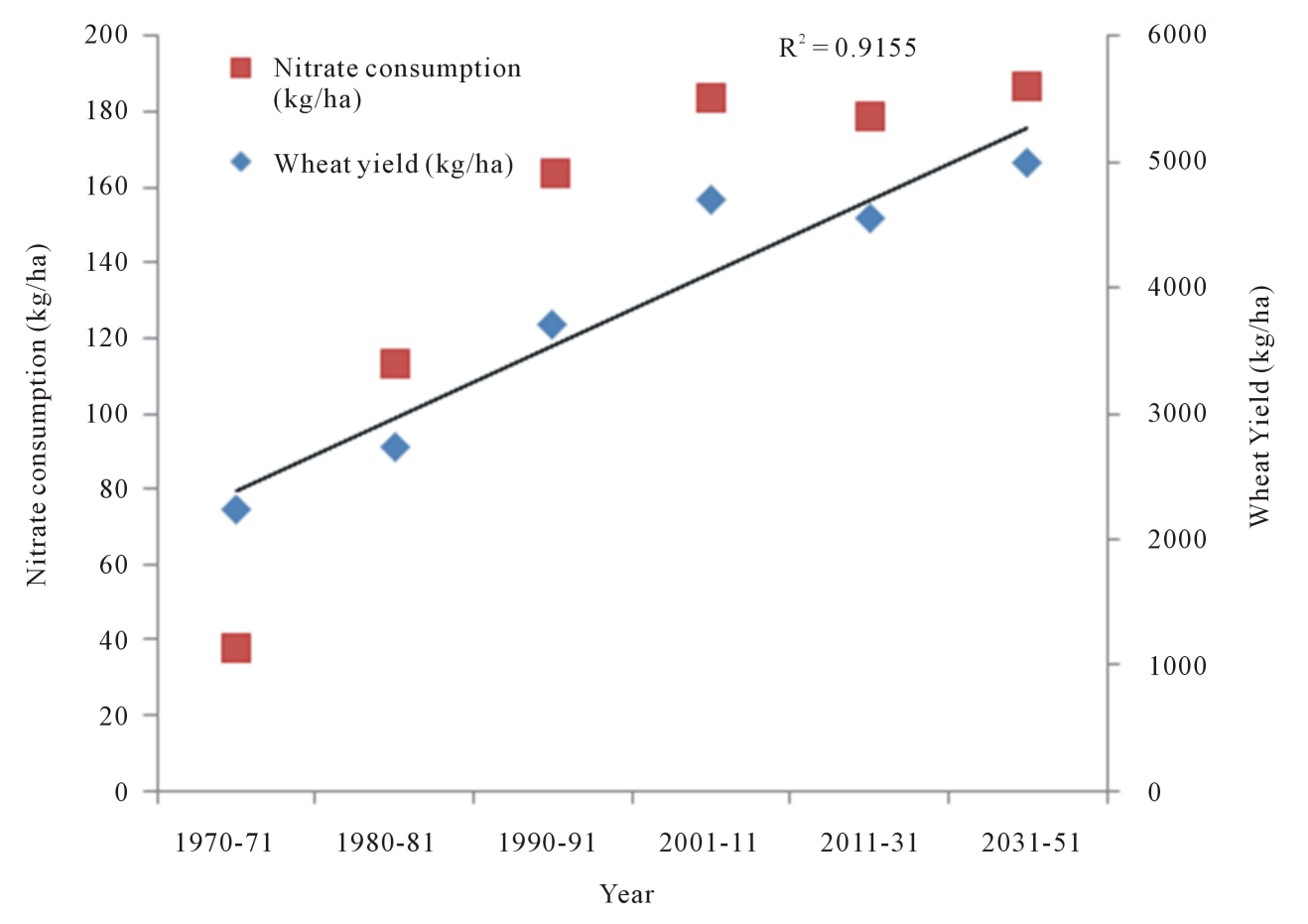

Figure 6. Correlation between wheat yield and consumption of nitrate in Punjab from 1970-71 to 2031-51. Source: FAOSTAT (2012).

of nitrogen to meet crop at each growth stage. The differences in water resources and the input use, particularly fertilizers, are quite high in the agriculture purposes. The use of fertilizers is relatively higher, leading to greater productivity of crops. The expansion of tube well irrigation, mainly due to free power in Punjab, is at the root of greater use of water and fertilizer and greater area under crops. In the context of groundwater demand, use and recharge will all be affected, leading to further depletion of groundwater levels due to nitrate concentration. There are three specific needs for effective and efficient agriculture (a) reduced the use of chemical fertilizers which leads to reduced production of reactive nitrogen, (b) recycling of agricultural waste by increased efficiency of reactive nitrogen use which helps to use reactive nitrogen in agro-ecosystem, and (c) increased denitrification of reactive nitrogen because that cannot be recycled, which will eliminate reactive nitrogen before it could leak to the environment.

\section{Note}

This work is not related to my United Nations work and responsibility.

\section{References}

[1] Gupta, A.P. (2005) Nitrogen Use Scenario of India. Science in China Ser. C Life Sciences, 48, 921-927.

[2] FAI (2010) Fertilizer Statistics 2005-06. Fertilizer Association of India, New Delhi.

[3] FAOSTAT (2012) FAO Agricultural Database, Food and Agricultural Organization. http://www.fao.org/nr/water/aquastat/water_use_agr/index2.stm

[4] He, B., Kanae, S., Oki, T., Hirabayashi, Y., Yamashiki, Y. and Takara, K. (2011) Assessment of Global Nitrogen Pollution in Rivers Using an Integrated Biogeochemical Modelling Framework. Water Research, 45, 2573-2586. http://dx.doi.org/10.1016/j.watres.2011.02.011

[5] Galloway, J.N. (2000) Nitrogen Mobilization in Asia. Nutrient Cycling in Agroecosystems, 57, 1-12. http://dx.doi.org/10.1023/A:1009832221034

[6] He, B., Oki, T. and Wang, Y. (2009) Using Remote Sensed Imagery to Estimate Potential Annual Pollutant Loads in River Basins. Water Science and Technology, 60, 2009-2015. http://dx.doi.org/10.2166/wst.2009.596

[7] IASRAI (2006) Agricultural Research Data Book. Indian Agricultural Statistics Research Institute, New Delhi. 
[8] Prasad, R. (2009) Efficient Fertilizer Use: The Key to Food Security and Better Environment. Journal of Tropical Agriculture, 47, 1-17.

[9] Annual Report Pb (2012) Annual report from Punjab Environmental Centre. http://punenvis.nic.in/index2.aspx?slid=201\&mid=1\&langid=1\&sublinkid=447

[10] Annual Report PSCST (2011) Punjab State Council For Science \& Technology. http://pscst.gov.in/files/ANNUAL\%20REPORT\%202011-12.pdf

[11] Khajuria, A., Yoshikawa, S. and Kanae, S. (2013) Estimation and Prediction of Water Availability and Water Withdrawal in India. Annual Journal of Hydraulic Engineering, Japan Society of Civil Engineering, (SUIKO), Ser. B1, 69, I_145-I_150.

[12] Heffer, P. (2009) Assessment of Fertilizer Use by Crop at the Global Level: 2006/07-2007/08. International Fertilizer Industry Association, Paris.

[13] Huang, G. (2013) Characterization of Nitrate Contamination in an Arid Region of China. Journal of Environmental Protection, 4, 46-52. http://dx.doi.org/10.4236/jep.2013.47A006 